\title{
EMPREENDEDORISMO INSTITUCIONAL:
}

\author{
UMA ANÁLISE DE CASO NO SETOR DE
}

ENERGIA ELÉT'RICA BRASILEIRO

\section{ILAN AVRICHIR}

Doutor em Administração de Empresas pela Escola de Administração de Empresas de

São Paulo da Fundação Getulio Vargas (FGV-SP).

Professor do Programa de Mestrado em Gestão Internacional da

Escola Superior de Propaganda e Marketing (ESPM).

Rua Álvaro Alvim, 123, Vila Mariana, São Paulo - SP - Brasil - CEP $01240-010$

E-mail: iavrichir@espm.br

\section{GABRIEL VOUGA CHUEKE}

Mestrando pelo Programa de Pós-Graduação em Gestão Internacional da Escola Superior de Propaganda e Marketing (ESPM). Rua Álvaro Alvim, 123, Vila Mariana, São Paulo - SP - Brasil - CEP $01240-010$

E-mail: gabrielbrasil@gmail.com

É permitido copiar, distribuir, exibir e transmitir essa obra; bem como criar obras derivadas, desde que se confira o devido crédito autoral e se referencie a publicação anterior na RAM (nome da revista, edição, ano e páginas) de forma explícita e clara (mas sem sugerir que a RAM apoia ou endossa o usuário ou o uso feito da obra). Por meio dessa licença, fica explicito a restrição ao uso da obra para fins comerciais. No caso de alteração, transformação ou adaptação dessa obra, você deve distribuir a obra resultante somente nas mesmas condições de licenciamento aqui estabelecidas. 


\section{RESUMO}

Este artigo busca contribuir para o entendimento do papel, das características e estratégias de indivíduos denominados na literatura acadêmica como empreendedores institucionais. Apesar do crescimento recente de pesquisas acerca do tema, os trabalhos sobre o nível do indivíduo são escassos. Para a consecução dos objetivos propostos, buscamos estudos que descrevessem a atuação de indivíduos como empreendedores institucionais. Revisamos cinco artigos publicados, no período de 2006 a 2009 , em revistas internacionais de alto impacto. Identificamos as características atribuídas aos empreendedores individuais nesses trabalhos, principalmente aquelas relacionadas às ações desses atores, em que etapa da mudança institucional atuaram e quais atributos lhes foram imputados. Confrontamos os resultados encontrados na revisão de literatura com o papel desempenhado por três empresários que criaram uma empresa privada pioneira no campo da comercialização de energia elétrica no Brasil, contribuindo para as transformações em curso no setor desde a década de I990. Descrevemos o contexto institucional em que atuaram, suas trajetórias pessoais e a atuação no campo. Como metodologia de pesquisa, adotamos o método de estudo de caso de caráter qualitativodescritivo. A fase de coleta de dados contou com múltiplas fontes de evidência, valendo-se principalmente de entrevistas em profundidade. Encontramos resultados predominantemente convergentes entre a literatura pesquisada e o caso analisado. Como contribuição, nosso estudo sugere que a atuação de agentes que promovem mudanças pode ser dividida em duas categorias principais quanto à sua extensão. Além disso, a análise do caso conduzido aponta para certo consenso sobre aspectos relacionados à atuação de indivíduos considerados na literatura acadêmica como empreendedores institucionais.

\section{PALAVRAS=CHAVE}

Empreendedorismo institucional; Estudo de caso; Análise sociológica; Estratégia; Setor de energia elétrica brasileiro. 


\section{INTRODUÇÃO}

Este artigo busca contribuir para o entendimento do papel, das características e estratégias de indivíduos qualificados como empreendedores institucionais (DIMAGGIO, I988). De acordo com a revisão realizada por Battilana, Leca e Boxembaum (2009), o nível do indivíduo tem sido pouco explorado na literatura acadêmica, que tem como centro de atenção o nível organizacional e o próprio campo organizacional como unidade de análise. Tal fato aponta para uma lacuna que apenas recentemente começa a ser preenchida. O conceito de empreendedor institucional surge na teoria organizacional na década de I980, formulado a partir dos estudos do sociólogo norte-americano Paul DiMaggio (I988). Apesar de sua ascensão acadêmica nos últimos 20 anos, que inspirou várias pesquisas no campo (DOUHAN; HEREKSON, 2008; INGRAM, 200I; LAWRENCE; PHILLIPS, 2004; LI; FENG; JIANG, 2006), são escassas as investigações que buscam entender as condições e contribuições de indivíduos nos processos de mudanças institucionais. Neste trabalho, analisamos cinco artigos publicados, no período de 2006 a 2009 , em revistas internacionais de alto impacto, buscando identificar em que medida eles coincidem ou divergem sobre os aspectos centrais da atuação desses agentes. Na sequência, usamos esses resultados para analisar o papel desempenhado por três empresários que criaram uma das empresas privadas pioneiras no campo da comercialização de energia elétrica no Brasil, no final da década de I990.

Atribui-se parte da importância que o conceito de empreendedor institucional adquire na literatura à possibilidade de contribuir para a resolução de um paradoxo do neoinstitucionalismo - a possibilidade de mudança. Para a teoria, indivíduos e organizações tendem a se comportar de acordo com as pressões institucionais às quais estão sujeitos (WACQUANT, I992; SELZNICK, I996; BOWERING, 2000). Portanto, torna-se difícil entender como as mudanças no ambiente institucional podem ocorrer, dado que a possibilidade de agência seria limitada. A noção de empreendedorismo institucional se apresenta como uma perspectiva capaz de lidar com esse paradoxo, ao enfatizar como os processos organizacionais e as instituições são configurados pela ação de empreendedores criativos (BATTILANA, 2006; PERKMANN; SPICER, 2008; GARUD; HARDY; MAGUIRE, 2007).

Além disso, vale observar que o tema empreendedorismo institucional parece particularmente relevante para países emergentes, dado que várias pesquisas, principalmente aquelas vinculadas à nova economia institucional (NEI), associam a não superação do subdesenvolvimento com a ineficiência das instituições, que aumentam o custo de produção ou transação. North (I990), por 
exemplo, afirma que, em países emergentes, as instituições, predominantemente, promovem a atividade redistributiva e não a produtiva, criam monopólios em vez de competição e restringem, em vez de ampliarem, as oportunidades. Shirley (2008) e Rodrik, Subramanian e Trebbi (2004) mostram que, apesar de inúmeras tentativas de reformas, a maioria dos países em desenvolvimento não foi capaz de romper com o baixo nível de equilíbrio: em parte, porque atores políticos e econômicos poderosos têm interesses em preservar as instituições atuais e, em parte, porque as crenças e os hábitos da sociedade apoiam e suportam o status quo.

A seguir, apresentamos os conceitos-chave para entendimento da definição de empreendedorismo institucional. Fazemos, também, uma revisão da literatura sobre o tema, destacando cinco trabalhos que discutem a participação de indivíduos em processos de mudanças institucionais. Posteriormente, traçamos o percurso metodológico da pesquisa de campo, à qual se filia a abordagem qualitativa, por meio do método de estudo de caso. Em seguida, fazemos a narrativa do caso pesquisado e seus principais incidentes críticos. Na sequência, apresentamos a análise e discussão dos resultados. E, por fim, tecemos conclusões e considerações finais.

\section{REFERENCIAL TEÓRICO}

Em 1988, Paul DiMaggio formula o conceito de empreendedor institucional, na tentativa de responder à pergunta sobre como surgem novas instituições (MAGUIRE; HARDY; LAWRENCE, 2004). Tal conceito, segundo Fligstein (2007), está alinhado com a tentativa de definir o papel independente e proativo dos atores nos processos de mudanças sociais, visto que empreendedores institucionais são capazes de envolver diversos grupos na (trans)formação de um campo e na determinação de sua estabilidade.

Os empreendedores institucionais podem ser definidos como atores que possuem interesses em determinados campos emergentes e são capazes de mobilizar recursos suficientes para criar uma nova instituição ou transformar uma já existente (DIMAGGIO, I988). Eles podem ser tanto organizações ou grupo de organizações, como indivíduos ou grupo de indivíduos. Entretanto, são escassos os estudos que se dedicam à figura do indivíduo como agente nesse processo (BATTILANA, 2006; BATTILANA; LECA; BOXEMBAUM, 2009; MENDONÇA; ALVES; CAMPOS, 20IO).

A habilidade de que os atores necessitam, tanto para construir como para reproduzir campos, consiste principalmente em motivar os outros, por meio 
de coalizões políticas, a tomar parte em uma ação coletiva (FLIGSTEIN, 2007). Requer, com frequência, estratégias discursivas que criam novos conceitos e dão suporte a novas ideias (MUNIR; PHILLIPS, 2005). Os empreendedores institucionais não apenas desempenham um papel tradicional, no sentido schumpeteriano, mas também ajudam no processo de evolução de sua atividade empresarial e na constituição de instituições de mercado. Como consequência de suas ações, incorrem, por um lado, em mais riscos e, por outro, têm maior potencial de produzir mais externalidades positivas para a economia, constituindo-se em importante força para o desenvolvimento econômico (LI; FENG; JIANG, 2006).

Com o objetivo de identificar fatores intrínsecos ao empreendedor institucional individual, presentes na literatura acadêmica, são analisados cinco trabalhos entre os anos de 2006 e 2009 , publicados em periódicos de relevância na área de estudos organizacionais, os quais, a partir da revisão da literatura, mostraram-se como referências centrais no campo. A seguir, é apresentada síntese dessas investigações em ordem cronológica.

O primeiro artigo analisado é o de Battilana (2006), que discute em que condições os indivíduos têm maior probabilidade de se engajar em processos de mudança. Na opinião da autora, a posição social do ator pode ser condição-chave para a caracterização do empreendedorismo institucional. Além disso, ter interesse em empreender mudanças e possuir recursos suficientes pode contribuir para alterar a lógica dominante (BOURDIEU, I990).

Battilana (2006), a partir da revisão da literatura existente, adianta proposições sobre a probabilidade de o indivíduo agir como empreendedor institucional em função da sua posição no campo. Com relação à organização a que ele pertence, a predisposição tende a ser menor se o status dessa for elevado. Organizações nessas condições tendem a mobilizar recursos para manter o status quo. Em contraposição, organizações menos centrais têm menos a perder com mudanças e pouco a perder com comportamentos desviantes, na medida em que são menos privilegiadas pelos arranjos existentes.

A posição dos atores no campo também é relevante para a predisposição à atuação como agentes da mudança. Pessoas com elevado status social, com frequência, se beneficiam do status quo, fato que diminuiria a sua propensão à ação. Profissões com elevado status social tenderiam a desempenhar papel conservador, para defender a autonomia e os privilégios. Por sua vez, indivíduos com baixo status social podem ter dificuldade em mobilizar recursos necessários para a condução de mudanças.

A posição dos indivíduos na hierarquia organizacional seria outro motivador dos processos de mudança. Indivíduos em posições inferiores não teriam legitimidade nem condições para acessar recursos para conduzir mudanças. Aqueles com posições de destaque podem se apoiar na autoridade e possuir informações 
sobre o ambiente institucional, fato que facilita a identificação de novos modelos organizacionais, que rompem com a lógica dominante no campo.

Quanto à posição social do indivíduo, se esta permitir maior probabilidade de estabelecer laços com outros atores de elevado status, possibilitará maior probabilidade de conduzir mudanças divergentes.

Estudo realizado por Li, Feng e Jiang (2006) parte da constatação de que as mudanças de leis, regulamentos e regras implícitas funcionam como fator impulsionador do rápido crescimento de várias economias emergentes, como China, Índia e Vietnã. Desse modo, os autores procuram analisar as estratégias que empreendedores institucionais utilizam para promover mudanças. Os autores definem o empreendedor institucional como uma pessoa inovadora que começa ou expande seu negócio e, no processo, ajuda a desconstruir e estabelecer instituições de mercado, no intento de tornar seu negócio bem-sucedido. Dessa forma, o empreendedor institucional deve possuir habilidades maiores do que o tradicional, que incluem, entre outras, lidar com os agentes governamentais e a opinião pública. Os empreendedores institucionais enfrentam maiores riscos e geram maiores externalidades para a economia, constituindo uma importante força econômica para o desenvolvimento e a reforma.

Com base em quatro estudos de casos chineses, Li, Feng e Jiang (2006) sustentam que há quatro abordagens, que os empreendedores institucionais empregam para quebrar barreiras ambientais:

- Advocacia aberta: defesa pública de mudanças em leis ou regulamentos, por meio de entrevistas na mídia, em fóruns e conferências abertas ou em pesquisas de opinião pública.

- Persuasão privada: argumentação, de caráter privado, junto a tomadores de decisão relevantes na sociedade, a partir de reuniões particulares ou patrocínio de relatórios de pesquisa não publicados, com intuito de convencer agentes governamentais.

- Pleitear exceção: defender a ideia de que se está diante de um caso especial e que este deve ser tratado como exceção às regras e aos regulamentos existentes, a fim de solicitar autorização para operar em caráter excepcional, apesar de incorrer em violação.

- Investimento ex ante com justificativa ex post: primeiro, o empreendedor começa ou expande o seu negócio, evadindo regulamentos ou regras existentes. Quando o negócio alcança sucesso e gera empregos ou benefícios sociais, o empreendedor usa esse sucesso para justificar seu comportamento anterior e persuadir o governo a alterar regulamentos ou regras para legitimar seu comportamento. 
Mutch (2007) concentra-se no caso de Sir Andrew Barclay Walker, empreendedor, que no final do século XIX, na Inglaterra, foi responsável pela disseminação de práticas gerenciais inovadoras entre as Public Houses (Pubs). Esse caso dá margem à discussão sobre o paradoxo da agência imbricada, o qual lida com a contradição que parece existir entre o papel condicionante que as instituições impõem ao agente e a mudança institucional, a qual pressupõe que o agente seja capaz de escapar dos fortes condicionamentos impostos pelo arcabouço institucional.

Mutch (2007) atribui a possibilidade de agência no nível individual à ocorrência de autonomia reflexiva, conceito desenvolvido anteriormente por Archer (2003). Mutch (2007) argumenta que a reflexividade autônoma é caracterizada por uma conversação interna ou atividade mental, cujos praticantes reconhecem como sendo um diálogo consigo mesmo e que dispensa as trocas com outras pessoas. Como consequência dessa atividade, os reflexivos autônomos se tornam estrategistas sociais, pois estão propensos a tomar decisões não desenvolvidas em conversação com o outro, sendo orientados a perseguir seus próprios projetos. Acredita-se que eles têm maior probabilidade de apresentar três condições características dos reflexivos autônomos: I. descontinuidade contextual na vida; 2. tendência a resolver conflitos potenciais ao priorizarem o trabalho; e 3. perfil de pessoas independentes e solitárias.

Com relação à trajetória de vida e às características pessoais de Sir Andrew, Mutch (2007) aponta que há indícios suficientes para sustentar que Andrew apresenta as três características dos reflexivos autônomos, e, portanto, sua ação como agente de mudanças pode ser caracterizada como um caso de empreendedorismo institucional.

Outra investigação de interesse, baseada em estudo longitudinal, é realizada por Svejenova, Mazza e Planellas (2007) que explora como empreendedores institucionais iniciam processos de mudança. Para ilustrar a questão, é estudada a trajetória do chefe de cozinha espanhol Ferran Adrià, proprietário de três renomados restaurantes, que contribui para o reconhecimento da nova cozinha espanhola em todo o mundo. Os autores sugerem que quatro fatores - criatividade, teorização, reputação e disseminação - seriam elementos-chave para o processo de mudança e legitimação de práticas ainda não institucionalizadas.

Com relação à criatividade, Svejenova, Mazza e Planellas (2007) destacam que o chefe usa um grande número de métodos para estimulá-la. Um deles seria a desconstrução, tomar um prato conhecido e alterar sua temperatura e a textura de todos ou alguns ingredientes. Sobre a teorização, processo de simplificação e abstração que desenvolve categorias e identifica propriedades e relações, os autores sustentam que Adrià internalizou esse mecanismo, enga- 
jando-se na ordenação da sua própria evolução numa síntese e num mapa evolucionário por meio de registros, autorreflexão e categorização. O chefe e sua equipe documentam escrupulosamente cada permutação que fazem no processo de experimentação.

A reputação é a definição prevalecente baseada no que a audiência sabe sobre o artista. É um processo de construção de consenso entre insiders relevantes. Svejenova, Mazza e Planellas (2007) atribuem a Adrià a habilidade de atrair a atenção e aprovação de gatekeepers legítimos e atores de alto status. Ele seria responsivo à mídia. Sua sensibilidade, disponibilidade e atenção para a mídia local e global foram essenciais para torná-lo renomado.

Já a disseminação é o mecanismo de difundir as novas ideias geradas por meio da criatividade e teorização, e que foram valorizadas pela reputação do chefe Adrià, que usa várias mídias para disseminar seu trabalho: DVDs, revistas e programas de rádio, além de livros. Os livros são de dois tipos, os que miram a elite e o mundo das artes, e aqueles voltados para o mercado de massa. O chefe também fez apresentações e cursos durante os períodos em que seu restaurante ficava fechado, voltado para cozinheiros novos e aspirantes.

Por último, o trabalho de Czarniawska (2009) utiliza referencial teórico inspirado na combinação da sociologia da translação (LATOUR, ı986; CZARNIAWSKA; SEVÓN, I996) e na teoria do ator-rede (CALLON; LATOUR, I98I; CZARNIAWSKA; HERNES, 2005) para criticar o papel heroico que os empreendedores institucionais adquirem nas teorias populares. Desse modo, Czarniawska (2009) busca descrever de forma realista a contribuição dos empreendedores institucionais para a emergência de novas instituições. Assim, o autor se vale extensivamente do relato de Ralf Dahrendorf sobre a história da London School of Economics (LSE), analisando o papel que vários atores tiveram no processo de criação, manutenção e institucionalização dessa universidade.

Czarniawska (2009) coloca em xeque o paradoxo da agência imbricada, argumentando que sempre existiram pessoas tentando criar instituições. A partir daí, descreve e analisa os contextos, as atuações e as consequências no processo de formação da LSE, procurando contribuir para a teoria sobre empreendedorismo institucional.

A análise do caso inicialmente concentra-se no casal Beatrice e Sideny Webb, atribuindo a eles o mérito de terem decifrado corretamente as mudanças no "idioma do dia", atraído patrocinadores e obtido doações, escrito o primeiro programa acadêmico da escola e dado várias entrevistas otimistas à imprensa. Apesar de sustentar que a LSE poderia ter sido construída por outros empreendedores ou sem eles, o casal em questão teria propiciado a estabilidade de que a instituição precisava no começo. 
No segundo período da história da LSE, que começa em i896, a escola vira um artefato. Atribui-se aos Webb a aquisição do prédio próprio e a constituição do corpo jurídico, fato que contribiu para que a escola alcançasse I.400 alunos oriundos de i6 países.

O período compreendido entre I9I9 e I937, durante o qual a LSE foi dirigida por Sir William Beveridge, é conhecido como segunda fundação. Um novo complexo de prédios foi construído, a maioria dos professores e alunos passou a se dedicar à instituição em período integral, biblioteca e salas de aula para os professores também foram construídas. O maior feito de Beveridge teria sido conseguir um auxílio da Fundação Rockfeller que representou, no período de i923 a I937, um quarto da receita da LSE. Czarniawska (2009) destaca que Beveridge era viciado em trabalho e autocrata, perseguia seus objetivos num nível que beirava a obsessão, uma característica que seria partilhada por muitos empreendedores institucionais. No último dos períodos analisados, o da normalização, a LSE se tornou uma universidade acusada de ser uma fábrica de diplomas, afastada da orientação inicial de ser uma escola de ciências sociais orientada para a prática. Nesse período, foi liderada por Alexander Carr Saunders, descrito como ponderado, sensato, prático, magnânimo, o diretor ideal para o período, mas não um empreendedor.

Czarniawska (2009) conclui que o caso sugere que dado o Zeigiest, espírito de época apropriado, surgiram empreendedores que "tomaram/traduziram/ inventaram" uma ideia adequada ao espírito e aos patrocinadores dispostos a responder ao chamado. Com relação às qualidades dos empreendedores institucionais, o que os distinguiria das outras pessoas seria o seu espírito empreendedor. Eles seriam equipados com grande quantidade de energia, seriam muito bons em forjar alianças e teriam um senso especial que lhes permitiria sentir o que está no ar. Teriam um talento para identificação de padrões. Estes não seriam habilidades e traços possíveis de ser ensinados ou aprendidos, apenas aperfeiçoados.

A seguir, com o propósito de sistematizar os achados levantados a partir da revisão dos artigos, apresenta-se um quadro esquemático que contém os principais elementos que auxiliam no entendimento do conceito e das características intrínsecas ao empreendedor institucional. 


\section{QUADRO I}

SÍNTESE DAS CARACTERÍSTICAS DE EMPREENDEDORISMO INSTITUCIONAL PRESENTES NA LITERATURA PESQUISADA

\begin{tabular}{|c|c|c|c|c|}
\hline AUTOR & OBJETIVO & $\begin{array}{l}\text { REFERENCIAL } \\
\text { TEÓRICO }\end{array}$ & $\begin{array}{l}\text { DEFINIÇÃO DE } \\
\text { EMPREENDEDOR } \\
\text { INSTITUCIONAL }\end{array}$ & $\begin{array}{l}\text { CONCLUSÕES SOBRE O } \\
\text { INDIVÍDUO QUE ATUA } \\
\text { COMO EMPREENDEDOR } \\
\text { INSTITUCIONAL }\end{array}$ \\
\hline $\begin{array}{l}\text { Battilana } \\
(2006)\end{array}$ & $\begin{array}{l}\text { Identificar as } \\
\text { condições em } \\
\text { que o indivíduo } \\
\text { tem maior } \\
\text { probabilidade } \\
\text { de atuar como } \\
\text { empreendedor } \\
\text { institucional. }\end{array}$ & $\begin{array}{l}\text { Teoria do } \\
\text { campo de } \\
\text { Bourdieu }\end{array}$ & $\begin{array}{l}\text { Indivíduo que } \\
\text { toma parte de } \\
\text { um processo de } \\
\text { implementação, } \\
\text { o qual altera a } \\
\text { lógica dominante } \\
\text { e promove } \\
\text { alternativas } \\
\text { às práticas. } \\
\text { institucionalizadas }\end{array}$ & $\begin{array}{l}\text { A posição social do } \\
\text { indivíduo no campo } \\
\text { organizacional } \\
\text { determina a } \\
\text { probabilidade de } \\
\text { ele atuar como } \\
\text { empreendedor } \\
\text { institucional. }\end{array}$ \\
\hline $\begin{array}{l}\text { Li, Feng e } \\
\text { Jiang (2006) }\end{array}$ & $\begin{array}{l}\text { Analisar } \\
\text { estratégias que } \\
\text { empreendedores } \\
\text { podem usar para } \\
\text { derrubar barreiras } \\
\text { institucionais } \\
\text { e promover } \\
\text { instituições } \\
\text { orientadas para o } \\
\text { mercado. }\end{array}$ & $\begin{array}{l}\text { Nova } \\
\text { economia } \\
\text { institucional }\end{array}$ & $\begin{array}{l}\text { Pessoa inovadora } \\
\text { que começa } \\
\text { ou expande } \\
\text { seu negócio. } \\
\text { Nesse processo, } \\
\text { colabora com a } \\
\text { desconstrução e o } \\
\text { estabelecimento } \\
\text { de instituições de } \\
\text { mercado, com o } \\
\text { objetivo de tornar } \\
\text { seu negócio bem- } \\
\text { sucedido. }\end{array}$ & $\begin{array}{l}\text { Há quatro abordagens } \\
\text { que os empreendedores } \\
\text { institucionais } \\
\text { empregam: } \\
\text { 1. advocacia aberta; } \\
\text { 2. persuasão privada; } \\
\text { 3. pleitear exceção; } \\
\text { 4. investimento ex ante } \\
\text { com justificativa ex } \\
\text { post. }\end{array}$ \\
\hline
\end{tabular}




\section{QUADRO I (CONTINUAC̣ÃO)}

SINTESE DAS CARACTERÍSTICAS DE EMPREENDEDORISMO INSTITUCIONAL PRESENTES NA LITERATURA PESQUISADA

\begin{tabular}{|c|c|c|c|c|}
\hline AUTOR & OBJETIVO & $\begin{array}{l}\text { REFERENCIAL } \\
\text { TEÓRICO }\end{array}$ & $\begin{array}{l}\text { DEFINIÇÃO DE } \\
\text { EMPREENDEDOR } \\
\text { INSTITUCIONAL }\end{array}$ & $\begin{array}{l}\text { CONCLUSÕES SOBRE } 0 \\
\text { INDIVÍDUO QUE ATUA } \\
\text { COMO EMPREENDEDOR } \\
\text { INSTITUCIONAL }\end{array}$ \\
\hline $\begin{array}{l}\text { Mutch } \\
\text { (2007) }\end{array}$ & $\begin{array}{l}\text { Contribuir para a } \\
\text { discussão sobre } \\
\text { o paradoxo } \\
\text { da agência } \\
\text { imbricada. }\end{array}$ & $\begin{array}{l}\text { Teoria do } \\
\text { discurso }\end{array}$ & $\begin{array}{l}\text { Atores são } \\
\text { empreendedores } \\
\text { institucionais } \\
\text { quando o } \\
\text { trabalho deles } \\
\text { afeta o discurso } \\
\text { que constitui as } \\
\text { instituições ou } \\
\text { os mecanismos } \\
\text { de conformidade } \\
\text { em um campo, } \\
\text { de forma } \\
\text { autointeressada. }\end{array}$ & $\begin{array}{l}\text { O empreendedor } \\
\text { institucional, } \\
\text { por ser reflexivo } \\
\text { autônomo, exibe } \\
\text { três características: } \\
\text { 1. descontinuidade } \\
\text { contextual nas suas } \\
\text { vidas; } 2 \text {. tendência } \\
\text { a resolver conflitos } \\
\text { potenciais, priorizando } \\
\text { o trabalho; e } \\
\text { 3. perfil de pessoas } \\
\text { independentes e } \\
\text { solitárias. }\end{array}$ \\
\hline $\begin{array}{l}\text { Svejenova, } \\
\text { Mazza e } \\
\text { Planellas } \\
\text { (2007) }\end{array}$ & $\begin{array}{l}\text { Explorar como o } \\
\text { empreendedor } \\
\text { institucional inicia } \\
\text { a mudança. }\end{array}$ & $\begin{array}{l}\text { Nova } \\
\text { sociologia } \\
\text { institucional }\end{array}$ & $\begin{array}{l}\text { Atores que } \\
\text { buscam alterar a } \\
\text { lógica existente. }\end{array}$ & $\begin{array}{l}\text { O empreendedor } \\
\text { institucional inicia } \\
\text { mudanças por meio de } \\
\text { quatro fatores: } \\
\text { 1. criatividade, } \\
\text { 2. teorização, } \\
\text { 3. reputação e } \\
\text { 4. disseminação. Estes } \\
\text { seriam elementos-chave } \\
\text { para o processo de } \\
\text { mudança e legitimação } \\
\text { de práticas ainda não } \\
\text { institucionalizadas. }\end{array}$ \\
\hline
\end{tabular}




\section{QuADRo I (CONCLUSÃO)}

SINTESE DAS CARACTERÍSTICAS DE EMPREENDEDORISMO INSTITUCIONAL PRESENTES NA LITERATURA PESQUISADA

\begin{tabular}{|c|c|c|c|c|}
\hline AUTOR & OBJETIVO & $\begin{array}{l}\text { REFERENCIAL } \\
\text { TEÓRICO }\end{array}$ & $\begin{array}{l}\text { DEFINIÇÃO DE } \\
\text { EMPREENDEDOR } \\
\text { INSTITUCIONAL }\end{array}$ & $\begin{array}{l}\text { CONCLUSÕES SOBRE O } \\
\text { INDIVÍDUO QUE ATUA } \\
\text { COMO EMPREENDEDOR } \\
\text { INSTITUCIONAL }\end{array}$ \\
\hline $\begin{array}{l}\text { Czarniawska } \\
\text { (2009) }\end{array}$ & $\begin{array}{l}\text { Criticar o papel } \\
\text { heroico que os } \\
\text { empreendedores } \\
\text { institucionais } \\
\text { adquirem nas } \\
\text { teorias populares } \\
\text { e buscar } \\
\text { descrição realista } \\
\text { da contribuição } \\
\text { que dão para } \\
\text { a emergência } \\
\text { de novas } \\
\text { instituições. }\end{array}$ & $\begin{array}{l}\text { Combinação } \\
\text { da sociologia } \\
\text { da } \\
\text { translação } \\
\text { e teoria do } \\
\text { ator-rede }\end{array}$ & $\begin{array}{l}\text { Uma pessoa } \\
\text { ou grupo que } \\
\text { tenta criar uma } \\
\text { instituição. }\end{array}$ & $\begin{array}{l}\text { Pessoas equipadas } \\
\text { com grande } \\
\text { quantidade de energia, } \\
\text { com habilidades } \\
\text { extraordinárias em forjar } \\
\text { alianças e senso especial } \\
\text { que Ihes permite } \\
\text { "sentir o que está no } \\
\text { ar", além do talento } \\
\text { para identificação de } \\
\text { padrões. }\end{array}$ \\
\hline
\end{tabular}

Fonte: Elaborado pelos autores.

\section{METODOLOGIA}

Com o propósito de compreender as estratégias e características intrínsecas aos empreendedores aqui estudados, optou-se pelo uso do método de estudo de caso único (STAKE, 2000; YIN, 2009), o qual permite compreender a dinâmica social de um espaço específico, podendo prover descrições, testar ou até mesmo, em alguns casos, gerar teorias (EISENHARDT, I989; EISENHARDT; GRAEBNER, 2007). Nesse sentido, nossa investigação se configura como um caso de caráter qualitativo-descritivo.

$\mathrm{Na}$ etapa de coleta de dados, foram usadas entrevistas semiestruturadas em profundidade, realizadas com os três fundadores da empresa. Para a entrevista com o nosso informante principal, usamos um roteiro com questões-chave sobre o tema que, ao longo da narrativa, fez emergir novas indagações.

Além disso, procuramos entender a trajetória da empresa estudada e os episódios críticos ao longo do processo de institucionalização do campo. Assim, optamos pela análise de documentos publicados na mídia; documentos elabora- 
dos pela própria empresa, como atas de reunião, website, materiais promocionais, brochuras, entre outros. Ainda, foram analisadas as regulamentações e normas técnicas desenvolvidas para o setor de energia elétrica brasileiro, material divulgado por associações de classe, matérias publicadas em periódicos empresariais, assim como trabalhos acadêmicos e dados secundários sobre o setor de energia elétrica brasileiro (cf. SAUER, 2002). O material coletado foi desenvolvido entre i993 e 20II.

A análise de dados buscou confrontar as informações levantadas por meio das fontes primárias e secundárias com a teoria levantada. Dessa forma, procuramos qualificar as estratégias usadas pelos empreendedores e pelos atores envolvidos, e as características intrínsecas aos empreendedores-alvo do caso (EISENHARDT, I989; STAKE, 2000; YIN, 2009). Para preservar a identidade das pessoas e das organizações envolvidas na narrativa, os nomes foram omitidos. A seguir, apresentamos o caso.

\section{- CASO DO SETOR DE ENERGIA ELÉTRICA BRASILEIRO}

O período abrangido entre I992 e I998 correspondeu, no Brasil, ao início da estabilização econômica e à adoção de políticas de base neoliberais de desenvolvimento. Nesse sentido, é estabelecida como medida-chave a busca por investimento direto estrangeiro e desenvolvimento de programas de privatização. Com base nessa premissa, o discurso governamental passou a advogar pela redução do papel do Estado nos setores de infraestrutura, por meio da transferência progressiva de atribuições para a iniciativa privada. Assim, vários setores passaram por transformações radicais de governança, regulação e dissolução de fronteiras entre segmentos industriais (RODRIGUES; CHILD, 2003).

O setor de energia elétrica não foi exceção à regra, sendo substancialmente afetado, representando $30 \%$ das privatizações ocorridas nesse período. Tradicionalmente, o setor era composto por empresas verticalizadas, as quais tinham como função a geração, distribuição e comercialização de energia. As transações entre os segmentos eram registradas apenas na contabilidade das empresas. Havia relativa despreocupação com a eficiência, visto que essas empresas estavam sob o controle do Estado, o que tornava desnecessário o estabelecimento de instrumentos contratuais formais para a comercialização de energia elétrica no país (ROSIN, 2008).

A quebra do monopólio para contratação de energia elétrica por consumidores se configurou pela Lei $n^{\circ} 9.074$, de I995, que estabeleceu que consumidores de médio e grande portes poderiam contratar o fornecimento de produtores inde- 
pendentes, ou seja, não estavam mais obrigados a fazê-lo por meio de concessionárias de distribuição locais.

Em I996, por meio do Projeto de Reestruturação do Sistema Elétrico Brasileiro (RE-SEB) dá-se formalmente início à concepção do novo arcabouço setorial. O projeto tinha como pressupostos "introduzir a competição onde fosse possível e a regulação onde necessária” (ROSIN, 2008).

No período de 1995 a 2006, foram criados sucessivos dispositivos legislativos que alteraram profundamente a convivência entre os agentes que faziam parte do Sistema Elétrico Brasileiro (SEB). Um dos primeiros passos no sentido de permitir a participação de novos atores no mercado veio por meio de um decreto no ano de 1993, que permitiu a formação de consórcios por empresas interessadas na geração de energia elétrica para seu próprio consumo. Em I995, a Lei $n^{\circ} 9.074$ criou a figura do Produtor Independente de Energia (PIE) que poderia comercializar a energia produzida para consumidores "livres". A regulamentação da produção por produtor independente ocorreu apenas em 2003. A criação da figura do PIE suscitou dúvidas de vários autores que questionaram a possibilidade de existirem, em um mesmo ambiente, empresas privadas e públicas (ROSIN, 2008).

Com base nesse contexto, analisa-se o caso de uma empresa, fundada por três empresários oriundos da área de construção civil, cujo objetivo é atuar na área de comercialização de energia elétrica, até então inexistente no país. Vale notar que dois sócios da empresa já haviam ocupado cargos de direção em um grande grupo nesse segmento, e o outro tinha relação de parentesco com um dos controladores da firma. Além disso, vale notar que um dos sócios-fundadores da empresa participou de comissões, no Ministério de Energia Elétrica, que ajudaram a elaborar o novo modelo de concessões de serviço público para particulares, gradativamente implantado a partir de I995, com a Lei $n^{\circ}$ 8.987. Os três empresários são profissionais de engenharia experientes, com décadas de atuação em grandes empresas e formados pelas escolas de engenharia mais reputadas do país.

O primeiro negócio de grande porte realizado pela empresa ocorreu em 2001/2002, sendo um projeto de execução e colocação em operação de uma central termoelétrica a gás, para um grupo de investidores imobiliários, que estava construindo um edifício comercial de alto padrão, numa região muito valorizada da cidade de São Paulo. A contratação da central ocorreu durante a crise no fornecimento de energia elétrica, que aconteceu no Brasil naquela época e que ficou conhecida como "apagão". As possibilidades criadas, na década anterior, pelo Plano de Prioridades de Termoelétricas (PPT), que visava estimular o investimento privado na geração de energia elétrica, contribuíram para a concretização do projeto. 
Primeiramente nós verificamos que todo o conjunto, o arcabouço regulatório feito na década 90 apontava para a possibilidade de consumidores comprarem diretamente a sua energia de geradores. Ou seja, uma grande empresa não precisa ficar na Eletropaulo ou na Light, ou onde quer que seja.

A instalação de uma central termoelétrica num edifício comercial, em uma área densamente habitada de uma grande cidade, nunca havia sido realizada antes no Brasil e demandou ações de convencimento por parte dos sócios da prestadora do serviço, junto à adquirente. Envolveu, também, prospecção de equipamentos em vários países, certificação desses nas agências reguladoras, elaboração e alteração de contratos junto às seguradoras, além da solução de problemas de engenharia, para o equacionamento de questões térmicas e acústicas que não haviam sido enfrentadas antes pela indústria nacional. O processo de convencimento dos investidores foi, no entanto, bastante facilitado pela existência de relações comerciais anteriores, entre o grupo adquirente e o grupo de construção civil, do qual dois dos sócios da empresa ofertante eram oriundos.

Pouco depois do término do racionamento de energia, em 2002, as condições de comercialização do gás e a disponibilidade de preços vantajosos para a viabilidade de termoelétricas a gás se alteram radicalmente. $\mathrm{O}$ excedente de gás, que existia antes do racionamento, deixa de existir, e o aumento do preço torna desinteressante esse tipo de solução. A empresa comercializou mais uma termoelétrica a gás e mudou, substancialmente, o tipo de negócio que realizava. Desenvolveu, então, seu segundo tipo de negócio.

Aproveitando o fato de que o conjunto do arcabouço regulatório, concedido na década I990, apontava para a possibilidade de consumidores comprarem diretamente a sua energia de geradores, a empresa começou a comercializar energia elétrica. Valendo-se também de suas relações anteriores, estabelecidas no período em que ocupavam cargos de direção no grupo de construção civil, os sócios procuraram uma grande operadora de telefonia fixa e propuseram o fornecimento de energia elétrica a custo inferior ao que pagavam naquela época.

[...] nós resolvemos, para essa insegurança regulatória, entrar com um produto que nós assumimos todo o risco da operação. E aí foi a grande sacada, entendeu? Então eu assumi o risco da operação e garanti um desconto fixo para o cliente.

Apesar de a Lei $n^{\circ} 9.074$, de I995, e de outras que a sucederam acenarem com a quebra do monopólio que se configurava entre os agentes de geração, transmissão e distribuição de energia elétrica, a compra, por parte de clientes, exceto aqueles muito grandes como a Votorantim, que havia tempos gozavam de 
um status especial nessa área, fora de suas concessionárias locais, nunca havia sido feita. É fácil imaginar os receios e as dúvidas que os dirigentes da empresa de telefonia experimentaram, ainda mais se considerarmos que, pela natureza da sua atividade, dependiam totalmente das distribuidoras de energia para alcançar seus clientes, visto que a rede de telefonia usa os postes, que são de propriedade daquelas, para sustentar sua rede de fios telefônicos.

Entre as dificuldades que tiveram que ser vencidas para viabilizar a venda de energia elétrica para a empresa de telefonia, além do convencimento dos seus diretores, estão: I. identificação de uma fonte de fornecimento - necessariamente uma pequena central elétrica $(\mathrm{PCH}$, central em fonte de geração hidráulica com potencial entre I.000 e $30.000 \mathrm{~kW}) ; 2$. convencimento, negociação, redação de contrato e contratação da energia junto à PCH; 3. negociação de contrato de transporte de energia elétrica junto aos distribuidores localizados entre a fonte da energia e o consumidor, distribuidores esses cujos interesses estavam, pelo menos potencialmente, sendo contrariados pela operação que quebrava seu monopólio; 4. esclarecimento de todos os detalhes envolvidos no balanço de energias alimentadas e consumidas junto à rede, balanço que teria que ser feito pela Administradora de Serviços de Mercado Atacadista de Energia Elétrica (Asmae), que, apesar de ter legalmente a obrigação de fazer isso, nunca havia se debruçado sobre as questões envolvidas nessa realização.

[...] foi uma brecha de uma lei que existia, 9.648, que nunca tinha sido exercida, que nós vendemos a ideia à empresa de telefonia, cumprimos com a questão do contrato performance e depois tivemos um processo de negociação muito intenso em todos os órgãos, inclusive na concessionária, que obviamente não queria perder o cliente, que envolveu processos judiciais, liminares etc. para que fosse exercido um direito a que o consumidor fazia jus.

Nós negociamos com as concessionárias, nós negociamos com o MAE hoje CCEE que é a Câmara de Comercialização de Energia Elétrica que também não estava preparada para fazer isso. Nós negociamos na Aneel que também não tinha nenhum caso a respeito, não tinha regulamentação, não tinha nada, né? E tivemos que interferir no aperfeiçoamento da lei, né?

Um episódio crítico, representativo das situações que a empresa pesquisada e a de telefonia fixa vivenciaram nesse processo, foi o da comunicação à concessionária, da intenção de a empresa de telefonia denunciar o contrato de fornecimento de energia em vigor e passar a comprar energia no mercado livre do agente de mercado, cuja trajetória estamos relatando. Seis meses antes do prazo 
previsto para o início do fornecimento da energia à empresa de telefonia pela comercializadora privada de energia, dentro do prazo estabelecido no contrato pelo distribuidor de energia tradicional, este foi formalmente comunicado de que, a partir de uma determinada data, a empresa de telefonia fixa não teria mais interesse na renovação do contrato de fornecimento. A empresa de telefonia fixa recebeu uma ata confirmando que o distribuidor havia sido comunicado e que concordava com o término do acordo. Uma semana antes do prazo estipulado para o início do fornecimento pela comercializadora privada, quando os contratos com os fornecedores de energia e todos os demais envolvidos já estavam firmados, a empresa de telefonia fixa recebeu uma carta da empresa de distribuição alegando que, em função da falta de um documento exigido pelo contrato, para comunicação da interrupção do fornecimento, ela não seria liberada do compromisso de continuar adquirindo energia elétrica do distribuidor local.

Esse comunicado dá origem a uma pequena batalha judicial: a distribuidora privada obtém, por duas vezes, liminares junto à Agência Nacional de Energia Elétrica (Aneel), o que garante a interrupção do contrato de fornecimento, e a distribuidora tradicional de energia consegue cassar outras tantas vezes essas liminares. A batalha terminou com um acordo entre a distribuidora, a empresa de telefonia e a empresa que é o foco deste trabalho, em que as duas últimas aceitaram diminuir o número de edifícios, cujo fornecimento de energia elétrica não seria mais feito pela distribuidora tradicional, passando de cerca de 20 para algo próximo da metade desse número. Em contrapartida, a distribuidora concordou que o número menor de edifícios seria liberado do contrato na data que interessava às outras partes e ofereceu à empresa de telefonia fixa serviços complementares, que proporcionariam economias expressivas. Essa alteração, que nada tinha a ver com o objeto inicial da negociação, representou para a empresa de telefonia uma economia mais vultosa do que a que ela realizou com a troca de fornecedor de energia.

No processo de implantação do modelo de fornecimento à empresa de telefonia, pelo menos dois regulamentos importantes para a operação da comercialização de energia fora do monopólio foram estabelecidos. O primeiro se deu no processo de interrupção do contrato de fornecimento de energia pelas distribuidoras aos seus clientes. Antes da regulamentação provocada pela empresa pesquisada, essa interrupção tinha que ser negociada e obtida de comum acordo entre fornecedor e cliente. Agora, a aceitação da cessação pela distribuidora seria compulsória se o consumidor cumprisse os prazos e as outras condições estabelecidas pelo contrato. A outra regulamentação foi dos sistemas de medição que as empresas não tradicionais de distribuição precisariam instalar junto a seus clientes. As concessionárias, num momento determinado, passaram a exigir sistemas de medição caros, que inviabilizavam a operação. Em função de gestões 
que a empresa fez junto à Aneel, esta realizou audiências públicas e terminou por proibir as concessionárias de condicionarem a migração do consumidor à instalação de sistemas de medição, enquanto não fosse definido pelo Operador Nacional do Sistema Elétrico (ONS) um sistema padrão.

No momento em que as concessionárias perceberam que era um direito líquido e certo, elas começaram a criar obstáculos na forma de, por exemplo, exigir um sistema de medição extremamente caro, que inviabilizasse as vantagens do investimento. Bom, aí nos fomos pra Brasília e tivemos diversas reuniões com a Aneel, que gerou audiências públicas e que, no final, depois eu posso até verificar exatamente pra você o despacho qual que é, proibiu as concessionárias de condicionarem a migração do consumidor ao sistema de medição enquanto não fosse definido pelo Operador Nacional do Sistema Elétrico (ONS) um sistema padrão.

Hoje, a empresa objeto desse estudo é uma das maiores compradoras nacionais de energia de PCHs, fornece energia para unidades em seiscentos municípios, é a maior consumidora de energia elétrica do Estado de São Paulo, além de representar mais de I\% do consumo de energia elétrica do Brasil e atuar intensivamente na geração da energia que comercializa.

\section{ANÁlise e discussão dos RESULTADOS}

A partir da descrição do caso apresentado, aponta-se que os agentes envolvidos no processo de transformação do setor de energia elétrica brasileiro podem ser caracterizados como empreendedores institucionais, uma vez que foram capazes de motivar outros atores, por meio de coalizões, a seguir uma ação específica, gerando mudanças no ambiente institucional em que estavam inseridos (FLIGSTEIN, 2007). No caso, há pelo menos duas evidências de que a atuação dos empreendedores, por meio da empresa que criaram para gerar e comercializar energia elétrica, fez pressão sobre as agências reguladoras, no sentido de estas definirem regras que estavam em aberto, diminuindo o nível de incerteza envolvido no processo.

Isso ocorreu primeiro na montagem de usinas termoelétricas a gás e, posteriormente, na comercialização de energia elétrica. Essas evidências se encontram nos episódios de manifestação da Aneel, sobre a natureza dos equipamentos de medição que as empresas de distribuição de energia elétrica podem exigir para a comercialização de energia usando suas redes para a distribuição. E no fato de 
que, no processo, também fica definido que as distribuidoras seriam obrigadas a concordar com a descontinuação dos contratos de fornecimento, desde que os clientes se manifestassem com a antecedência devida, seguindo as cláusulas estipuladas nos contratos. Dessa forma, podemos evidenciar que a atuação dos empreendedores contribuiu para o enfraquecimento do monopólio no setor de energia elétrica brasileiro. Além disso, é interessante observar que há uma redução no custo de transação, dado que o preço é reduzido, apesar de a energia continuar a ser gerada e distribuída da mesma forma como antes, excluindo, então, a possibilidade de ser o custo de produção que teria sido reduzido. Portanto, essas mudanças caracterizam uma evolução na atividade empresarial do setor e uma reconfiguração das instituições de mercado (LI; FENG; JIANG, 2006).

Com relação às condições que predispõem ao empreendedorismo institucional individual, propostas por Battillana (2006), a posição dos três empresários no campo organizacional são predominantemente consistentes com elas. Os indivíduos estavam em organizações de baixo status, uma empresa entrante, portanto pouco centrais no campo organizacional e pouco privilegiadas pelos arranjos existentes. Eles tinham elevado status na organização, eram os sócios-diretores, o que lhes possilitava acesso a recursos e informações sobre o ambiente, fato que lhes facultou identificar modelos que, se não se constituíam na ruptura da lógica dominante, como propõe a autora, pelo menos contribuíram para que o rompimento acontecesse. A mobilidade, definida pela autora como fluxo de administradores de topo entre organizações e campos, que propicia experiência, exposição a diferentes contextos organizacionais e conhecimento de arranjos heterogêneos, também está presente, na medida em que os três empresários chegam ao setor de energia elétrica, vindos de outros. A condição cuja ocorrência no caso se pode discutir é a de que indivíduos que pertencem a grupos com baixo status social são os que têm maior probabilidade de realizar mudanças divergentes. Os empresários claramente dispunham de capital financeiro, social e simbólico elevado, contrariamente ao argumento de Battilana (2006). Contudo, a própria autora problematiza essa condição de baixo status, indicando que indivíduos que a preenchem tendem a ter dificuldades de acesso a recursos-chave necessários para condução de mudanças (BATTILANA, 2006, p. 664).

É notória a semelhança entre a abordagem que os empresários adotaram no caso e a que Li, Feng e Jiang (2006) denominam persuasão privada, a argumentação, junto a tomadores de decisão relevantes na sociedade, a partir de reuniões particulares. A definição que os autores dão à abordagem parece descrever perfeitamente e colocar em relevo a essência da ação que os empresários do caso tiveram, seja na sua tentativa de influenciar os primeiros clientes a aceitar a proposta do novo serviço, seja na tentativa de obter a aprovação de órgãos governamentais, Aneel, MAE, concessionários, resoluções e atuações condizentes com 
os seus interesses. A palavra "negociar" é a mais recorrente na descrição que os empresários fazem da sua atuação.

Pela própria natureza privada e não observável da reflexão autônoma, é difícil sustentar se os empresários praticam "conversações internas vis-à-vis interações transpessoais", condição definidora do empreendedor institucional de Mutch (2007, p. II28). Essa dificuldade é reconhecida pelo próprio autor na análise que faz do agente central do seu caso. Das características decorrentes da reflexividade autônoma que o autor relaciona - individualismo, priorização do trabalho e descontinuidade contextual -, só a segunda parece presente, com alguma clareza, na situação que analisamos diretamente. Com relação ao individualismo, à baixa propensão à exposição pública e privada, à descontinuidade contextual e ao padrão de movimentação, segundo Mutch (2007), não há dados para afirmar se se trata de condições que são atendidas ou não pelos atores centrais do caso.

Das descrições que relacionamos sobre a atuação de indivíduos na condição de empreendedores individuais, as atribuídas por Svejenova, Mazza e Planellas (2007) ao chefe Adrià são as que menos se aproximam das que encontramos no caso. Com exceção talvez da criatividade, não podemos sustentar que os três empresários tenham se destacado em empenho ou competência, seja na teorização, criação de reputação ou disseminação da mudança provocada. Nesse sentido, tendemos a considerar que eles pendem mais para a baixa propensão à exposição pública a que alude Mutch (2007) do que a buscar atenção e projetar suas ideias. Atribuímos a não verificação dessas condições ao fato de o setor analisado por Svejenova, Mazza e Planellas (2007) ser diferente daquele apresentado aqui. Como, porém, esses autores sustentam que o modelo se aplica aos estágios iniciais da mudança institucional, sem restringir ou qualificar setor, o fato de os mecanismos descritos não terem sido verificados na mudança que analisamos não deixa de ser uma contribuição à sua pesquisa.

Contrariamente ao que acontece com os mecanismos sugeridos por Svejenova, Mazza e Planellas (2007), as características do indivíduo empreendedor institucional descritas por Czarniawska (2009) são consistentes com as exibidas pelos atores do nosso caso. À semelhança dos professores britânicos que tiveram atuação relevante para a institucionalização da LSE, os empresários do caso também parecem ter demonstrado, na situação, grandes quantidades de energia, senso especial para identificar, numa mudança que estava no ar, oportunidade de realização de objetivos e habilidades de forjar alianças complexas envolvendo clientes, órgãos reguladores, concessionárias. À semelhança do que faz Czarniawska, também podemos especular se, caso os três empresários não tivessem desempenhado o papel que desempenharam, outros não o teriam feito e se não seria possível construir uma narrativa da mudança que, sem diminuir o protagonismo dos empresários - seu heroísmo, nos termos da autora -, fosse 
mais realista, multiplicando o número de atores reconhecidos e enfatizando a conexão entre eles.

Por último, acreditamos que os casos analisados permitem sustentar que as ações dos indivíduos como empreendedores institucionais podem ser agrupadas em duas categorias quanto à sua extensão: ou elas são pequenas contribuições em mudanças de grandes proporções ou amplas em alterações menores. Na primeira categoria, incluímos a atuação do chefe Adrià que contribui marginalmente para a afirmação da nouvelle cuisine, um movimento de impacto em âmbito internacional; as ações dos empresários chineses, descritos por Li, Feng e Jiang (2006), que dão início a reformas localizadas, num contexto de profunda mudança econômica e institucional na China; e o apresentado por nós, em que empresários antecipam aspectos pontuais de uma grande mudança no setor de energia elétrica no Brasil. Na segunda categoria, consideramos o caso do empreendedor britânico, que altera significativamente a forma de gestão de um setor localizado numa região especifica da Inglaterra, e a atuação de professores, que praticamente criam uma instituição de ensino que, apesar de muito reconhecida, é uma de inúmeras do sistema educacional de nível superior inglês.

\section{CONSIDERAÇÕES FINAIS}

Como base em estudo de um caso no setor de energia elétrica brasileiro, descrevemos e analisamos a história de três empresários que desempenham um papel pioneiro na implementação da figura do comercializador de energia elétrica. Confrontamos as características e abordagens que utilizam com as que identificamos em cinco artigos publicados em revistas de alto impacto sobre o tema, que também destacam a atuação de indivíduos, e encontramos consistência e, na maioria das vezes, diferenças significativas.

Este estudo permitiu verificar se as proposições existentes na literatura sobre o indivíduo como empreendedor institucional, principalmente com relação às suas características, ocorreram em situação diferente da originalmente proposta, com resultados predominantemente positivos. Além disso, permitiu-nos sugerir que a atuação dos indivíduos pode ser dividida em duas categorias quanto à sua extensão. A revisão da literatura que fizemos e a análise do caso conduzido sugerem que começa a emergir, numa área antes carente de pesquisa, certo consenso sobre alguns aspectos do indivíduo, quando atua como empreendedor institucional. Esse consenso se realiza, em que pese a diversidade de objetivos, em referenciais teóricos e metodologias usados pelos autores.

Vale ressaltar, como limitação do estudo, que nossa pesquisa é de caráter preliminar, o que não permite o estabelecimento de conclusões definitivas a 
respeito do assunto. Contudo, nossa investigação procurou contribuir para o aumento do conhecimento empírico acerca do empreendedorismo institucional, podendo ser um ponto de partida para pesquisas futuras que visem entender melhor esse fenômeno e sua importância para o desenvolvimento econômico de países emergentes.

\section{INSTITUTIONAL ENTREPRENEURSHIP: AN ANALYSIS OF A CASE IN THE BRAZILIAN ELECTRIC POWER SECTOR}

\section{ABSTRACT}

This article seeks to contribute to the understanding of the role, characteristics and strategies of individuals when they act as what the academic literature categorizes as institutional entrepreneurs. Despite the recent growth of research on the subject of institutional entrepreneurship, work on the individual level continues to be scarce. To achieve our objectives, we probe the literature in search of papers that focuses the actions of individuals as institutional entrepreneurs. We review five articles published in high impact international journals between 2006 to 2009 . We identify the individual characteristics of the entrepreneur in these papers, especially those related to the actions of these actors, the stage of institutional change at which they acted and what attributes have been ascribed to them. After that, we confront the results found in the literature review with the role of three entrepreneurs who have created a private company and pioneered the field of commercialization of electric power in Brazil, contributing to the changes taking place in that industry during the r990s. We describe the institutional context in which they worked, their personal trajectory and the role they played in the field. As research methodology, we adopt the case study method. The phase of data collection relied on multiple sources of evidence, mainly deep interviews. We find predominantly convergent results between the literature and the case analyses. As a contribution, our study suggests that the activities of agents can be divided into two main categories as to their extension. In addition, the analysis of the case study suggest the emergence of a certain consensus about the acting of individuals acting as institutional entrepreneurs.

\section{KEYWORDS}

Institucional entrepreneur; Case study; Sociological institutionalism; Strategy; Brazilian electric power sector. 


\section{EMPRENDEDORISMO INSTITUCIONAL: UNA ANÁLISIS DE CASO EN EL SECTOR DE ENERGÍA ELÉCTRICA BRASILEÑO}

\section{RESUMEN}

Este trabajo busca contribuir para la comprensión del papel, características y estrategias de individuos cualificados como emprendedores institucionales. A pesar del fuerte atractivo de la propuesta, son pocos los estudios empíricos que tratan sobre el tema. Nuestro trabajo, analiza cinco estudios publicados en el período de 2006 a 2009 , en periódicos internacionales de alto impacto. Así, son utilizados conceptos oriundos de la sociología institucional, también, elementos de la teoría económica, en la búsqueda por aproximación entre las disciplinas de estrategia y la perspectiva sociológica. Apuntamos algunos aspectos que se relacionan con el paradojo de la agencia imbricada y elementos que caracterizan la acción y ayudan en la conceptuación de lo que es emprendedorismo institucional. En la etapa de análisis, los resultados encontrados en la revisión de literatura son confrontados con la actuación de tres empresarios que crean una empresa privada pionera en el campo de comercialización de energía eléctrica en Brasil, contribuyendo para las transformaciones en curso en el sector de energía eléctrica en la década de I990. La metodología adoptada en esta investigación se configura como un caso de carácter cualitativo-descriptivo. La etapa de colecta de datos utilizo múltiples fuentes de evidencia. El trabajo busco averiguar si las proposiciones existentes en la literatura sobre el individuo como emprendedor institucional, principalmente en relación a sus características, se confirman en una situación distinta de la originalmente propuesta, con resultados predominantemente positivos. También, sugerimos que la actuación de los individuos puede ser dividida en dos categorías cuanto a su extensión. La análisis del caso conducido también sugiere que empieza a emerger cierto conceso sobre algunos aspectos del individuo cuando actúa como emprendedor institucional.

\section{PALABRAS CLAVE}

Emprendedorismo institucional; Estudio de caso; Análisis sociológica; Estrategia; Sector de energía eléctrica brasileño. 


\section{REFERÊNCIAS}

ARCHER, M. S. Structure, agency and the internal conversation. Cambridge: Cambridge University Press, 2003.

BATTILANA, J. Agency and institutions: the enabling role of individuals' social position. Organization, v. I3, n. 5, p. 653-676, 2006.

BATILLANA, J.; LECA, B.; BOXEMBAUM, E. Agency and institutions: a review of institutional entrepreneurship. Academy of Management Annals, v. 3, p. 65-107, 2009.

BOURDIEU, P. The logic of practice. California: Stanford University Press, I990.

BOWERING, M. Construction theory: a look at the institutional theory that positivism built. Journal of Management Inquiry, v. 9, n. 3, p. 258-I75, 2000.

CALLON, M.; LATOUR, B. Unscrewing the big leviathan: how actors macro-structure reality and how sociologist help them to do so. In: KNORRCETIN, A. K.; CICOUREL, A. (Ed.). Advances in social theory and methodology: toward an integration of micro and macro-sociologies. Boston: Routledge \& Kegan Paul, I98I. p. 277-303.

CZARNIAWSKA, B. Emerging institutions: pyramids or anthills? Organization Studies, v. 30, n. 4, p. 423-44I, 2009 .

CZARNIAWSKA, B.; HERNES, T. (Ed.). Actor-network theory and organizing. Copenhagen: Copenhagen Business School Press, 2005.

CZARNIAWSKA, B.; SEVÓN, G. Translating organizational change. Berlin: Walter de Gruyter, I996.

DIMAGGIO, P. Interest and agency in institutional theory. In: L. ZUCKER (Ed.). Institutional patterns and organizations. Cambridge: Ballinger, I988.

DOUHAN, R.; HEREKSON, M. Entrepreneurship and second-best institutions: going beyond Baumol's typology. Stockholm: Research Institute of Industrial Economics, 2008.

EISENHARDT, K. M. Building theories from case study research. Academy of Management Review, v. I4, p. 532-550, I989,

EISENHARDT, K. M; GRAEBNER M. E. Theory building from cases: opportunities and challenges. Academy of Management Review, v. 50, n. I, p. 25-32, 2007.

FLIGSTEIN, N. Social skills and the theory of fields. Sociological Theory, v. I9, n. 2, p. I05-I25, 200 I. . Habilidade social e a teoria dos campos. Revista de Administração de Empresas, São Paulo, v. 2, n. 47 , p. 6I-80, 2007

GARUD, R.; HARDY, C.; MAGUIRE, S. Institutional entrepreneurship as embedded agency: an introduction to the special issue. Organization Studies, v. 27, n. 7, p. 957-969. 2007.

INGRAM, P. Changing the rules: interests, organizations, and institutional change in the US hospitality industry. In: BRINTON M. C.; NEE, V. (Ed.). The new institutionalism in sociology. Stanford: Stanford University Press, 200I.

LATOUR, B. The powers of association. In: LAW, J. (Ed.). Power, action and belief: a new sociology of knowledge? London: Routledge \& Kegan Paul, I986. p. 264-280.

LAWRENCE, T. B.; PHILLIPS, N. From Moby Dick to Free Willy: macro-cultural discourse and institutional entrepreneurship in emerging institutional fields. Organization, v. II, n. 5, p. 689-7II, 2004 . 
LI, D. D.; FENG, J.; JIANG, H. Institutional entrepreneurs. American Economic Association, v. 96, n. 2, p. 358-362, 2006.

MAGUIRE, S.; HARDY, C.; LAWRENCE, T. B. Institutional entrepreneuship in emerging fields: HIV/Aids treatment advocacy in Canada. Academy of Management Journal, v. 47, n. 5, p. 657-679, 2004 .

MENDONÇA, P. E. M.; ALVES, M. A.; CAMPOS, L. C. Empreendedorismo institucional na emergência do campo de políticas públicas em HIV/Aids no Brasil, Revista de Administração de Empresas, São Paulo, v. 9, n. I, jan./jun. 20Io.

MUNIR, K. A.; PHILLIPS, N. The birth of the "Kodak Moment": institutional entrepreneurship and the adoption of new technologies. Organization Studies, v. 26, n. II, p. I665-I687, 2005.

MUTCH, A. Reflexivity and the institutional entrepreneur: a historical exploration. Organization Studies, v. 27, n. 7, p. II23-II40, 2007.

NORTH, D. C. Institutions, institutional change and economic performance. New York: Cambridge University Press, I990.

PERKMANN, M.; SPICER, A. How are management fashions institutionalized? The role of institutional work. Human Relations, v. 6I, n. 6, p. 8II-844, 2008.

RODRIGUES, S.; CHILD, J. M. Co-evolution in an institutionalized environment. Journal of Management Studies, v. 40, p. 2137-2162, 2003.

RODRIK, D.; SUBRAMANIAN, A.; TREBBI, F. Institutions rule: the primacy of institutions over geography and integration in economic development. Journal of Economic Growth, v. 9, p. I3I-I65, 2004 .

ROSIN, S. O. Geração de energia elétrica: um enfoque histórico e institucional das questões comerciais no Brasil. 2008. Dissertação (Mestrado em Energia)-Universidade de São Paulo, São Paulo, 2008.

SAUER, I. Um Novo modelo para o setor elétrico brasileiro. São Paulo: IEE/USP, 2002.

SELZNICK, P. Institutionalism "old" and "new". Administrative Science Quarterly, v. 4I, n. 2, p. 270277, 1996.

SHIRLEY, M. M. Institutions and development. In: MÉNARD, C.; SHIRLEY, M. M. Handbook of New Institutional Economics. Berlin: Springer, 2008. p. 6II-638.

STAKE, R. E. Case studies. In: DENZIN, N. K; LINCOLN, Y. S (Ed.). Handbook of qualitative research. London: Sage; 2000.

SVEJENOVA, S.; MAZZA, C.; PLANELLAS, M. Cooking up change in haute cuisine: Ferran Adrià as an institutional entrepreneur. Journal of Organizational Behavior, v. 28, p. 539-56I, 2007.

WACQUANT, L. J. D. Toward a social praxeology: the structure and logic of Bourdieu's sociology. In: BOURDIEU, P.; WACQUANT, L. J. D. An invitation to reflexive sociology. Chicago: Chicago University Press, I992.

YIN, R. K. Case study research: design and methods. London: Sage, 2009. 